\title{
Detection of persistent Plasmodium spp. infections in Ugandan children after artemether-lumefantrine treatment
}

\author{
MARTHA BETSON ${ }^{1}$, JOSÉ C. SOUSA-FIGUEIREDO ${ }^{2}$, AARON ATUHAIRE ${ }^{3}$, \\ MOSES ARINAITWE ${ }^{3}$, MOSES ADRIKO ${ }^{3}$, GERALD MWESIGWA ${ }^{3}$, JUMA NABONGE ${ }^{4}$, \\ NARCIS B. KABATEREINE ${ }^{3}$, COLIN J. SUTHERLAND ${ }^{2}$ and J. RUSSELL STOTHARD ${ }^{5}$ * \\ ${ }^{1}$ Department of Production and Population Health, Royal Veterinary College, Hatfield, Hertfordshire, UK \\ ${ }^{2}$ Faculty of Infectious and Tropical Diseases, London School of Hygiene and Tropical Medicine, London, UK \\ ${ }^{3}$ Vector Control Division, Ministry of Health, Kampala, Uganda \\ ${ }^{4}$ Vector Control Division, Mayuge District, Uganda \\ ${ }^{5}$ Department of Parasitology, Liverpool School of Tropical Medicine, Liverpool, UK
}

(Received 19 December 2013; revised 14 February 2014; accepted 23 February 2014; first published online 16 May 2014)

SUMMARY

During a longitudinal study investigating the dynamics of malaria in Ugandan lakeshore communities, a consistently high malaria prevalence was observed in young children despite regular treatment. To explore the short-term performance of artemether-lumefantrine (AL), a pilot investigation into parasite carriage after treatment(s) was conducted in Bukoba village. A total of 163 children (aged 2-7 years) with a positive blood film and rapid antigen test were treated with AL; only $8 \cdot 7 \%$ of these had elevated axillary temperatures. On day 7 and then on day 17,40 children (26.3\%) and $33(22 \cdot 3 \%)$ were positive by microscopy, respectively. Real-time PCR analysis demonstrated that multi-species Plasmodium infections were common at baseline, with $41 \cdot 1 \%$ of children positive for Plasmodium falciparum/Plasmodium malariae, $9 \cdot 2 \%$ for P. falciparum/ Plasmodium ovale spp. and $8.0 \%$ for all three species. Moreover, on day 17, 39.9\% of children infected with falciparum malaria at baseline were again positive for the same species, and $9 \cdot 2 \%$ of those infected with $P$. malariae at baseline were positive for $P$. malariae. Here, chronic multi-species malaria infections persisted in children after AL treatment(s). Better point-of-care diagnostics for non-falciparum infections are needed, as well as further investigation of AL performance in asymptomatic individuals.

Key words: artemisinin combination therapy, malaria, rapid diagnostic test, Uganda, Plasmodium falciparum, Plasmodium malariae, Plasmodium ovale.

\section{INTRODUCTION}

Malaria remains a substantive public health problem in Uganda, particularly in young children. Challenges to effective malaria control in this country include an extremely high transmission intensity with entomological inoculation rates greater than 100 per year in many areas, a weak health system with a fragile supply chain for front-line antimalarial treatments, inadequate case management with poor diagnostic tools in rural health centres and ineffective monitoring and evaluation of control interventions (Yeka et al. 2012). To reduce the burden of clinical disease, Uganda adopted a fixed dose artemisinin combination therapy (AC'T) of artemether-lumefantrine (AL), as its first-line treatment for uncomplicated falciparum malaria in 2006 (Batwala et al. 2010) and a number of trials indicate that AL is highly efficacious and safe in this country (Bukirwa et al. 2006; Dorsey et al. 2007; Kamya et al. 2007; Yeka et al.2008; Achan et al. 2009; Arinaitwe et al. 2009; Bassat et al. 2009;

* Corresponding author: Department of Parasitology, Liverpool School of Tropical Medicine, Pembroke Place, Liverpool L3 5QA, UK. E-mail: jrstoth@liv.ac.uk
The Four Artemisinin-Based Combinations (4ABC) Study Group, 2011). Despite concerns about non-compliance i.e. non-completion of the 3 -day course of antimalarial therapy, high levels of adherence to home-based AL treatment and very similar high cure rates were found in a trial comparing unsupervised and supervised treatment (Fogg et al. 2004; Piola et al. 2005).

Since ACTs are relatively expensive and to ensure correct clinical management of febrile illness, the World Health Organization (WHO) promotes a 'test-and-treat' strategy for malaria involving parasitological diagnosis rather than presumptive treatment based on clinical indicators (WHO, $2010 a$ ). The gold standard for malaria diagnosis remains light microscopy, however, this can be difficult to implement in rural clinical settings due to a shortage of equipment and trained staff. Many African countries, including Uganda, are now introducing rapid diagnostic tests (RDTs) for malaria diagnosis in local health centres and for communitybased malaria management (Drakeley and Reyburn, 2009). However, as there are a plethora of RDTs for detection of falciparum and vivax malaria produced 
by a range of manufacturers, which vary in format and diagnostic performance, adoption of the 'best' test can be problematic (WHO, 2012). Common antigen targets for RDTs, histidine-rich protein 2 (HRP2; Plasmodium falciparum-specific) and lactate dehydrogenase (LDH; pan-Plasmodium or speciesspecific), display marked differences in their sensitivity, stability and dynamics of clearance from the blood after antimalarial treatment (Aydin-Schmidt et al. 2013; Nyunt et al. 2013).

Although $P$. falciparum remains the major cause of morbidity and mortality in sub-Saharan Africa, non-falciparum infections, such as Plasmodium vivax, Plasmodium malariae and Plasmodium ovale spp., are also present in humans and their clinical significance should not be overlooked (Collins and Jeffery, 2005, 2007; Mueller et al. 2007, 2009). Plasmodium malariae and P. ovale spp. infections, in particular, are often challenging to diagnose by microscopy due to low parasitaemias and difficulties in distinguishing from $P$. falciparum, particularly in cases of mixed infection (Mueller et al.2007). In fact, PCR-based methods have revealed that $P$. malariae and $P$. ovale spp. are more prevalent in sub-Saharan Africa than previously thought based on microscopic diagnosis (Mueller et al. 2007, 2009; Bruce et al. 2008; Oguike et al. 2011; Proietti et al. 2011). Unfortunately these methodologies are not readily deployed in remote resource-poor settings and the RDTs tested to date generally show poor diagnostic performance in detection of $P$. malariae and $P$. ovale spp. infections in individuals (Maltha et al. 2013a,b). In non-immune travellers, the sensitivities of RDTs range from $21 \cdot 4$ to $85 \cdot 7 \%$ for $P$. malariae detection and from $5 \cdot 5$ to $86 \cdot 7 \%$ for $P$. ovale (Houzé et al. 2011; Maltha et al. 2013b). There has been very little reported on the diagnostic performance of RDTs for these malaria species in endemic settings, likely due to their low prevalence (as detected by microscopy) and the fact that they often exist as mixed infections with other malaria species.

In line with national treatment guidelines and to develop a strategy for treatment of schistosomiasis in under $5 \mathrm{~s}$, a closed-cohort longitudinal study was initiated in 2009 investigating schistosomiasis and malaria in mothers and young children living in six communities in Uganda (the Schistosomiasis in Mothers and Infants or SIMI project) (Betson et al. 2010). Over the course of this project AL was provided to all RDT-proven malaria cases at the time of the survey(s). Although on-site treatment decisions were based on RDT results, the vast majority of RDT-positives were subsequently shown to be parasitaemic by microscopy and PCR (SousaFigueiredo et al. 2010). In addition, we observed a substantial number of cases of co-infection of $P$. falciparum with $P$. malariae and/or $P$. ovale spp. (Oguike et al. 2011). More importantly, we noticed that many children in these areas of intense malaria transmission required repeated $\mathrm{AL}$ treatment, up to five times within 18 months. At the end of this longitudinal study, we considered that a pilot study was needed to gather evidence on the effectiveness of AL against $P$. falciparum and non-falciparum malaria in this setting. Here we report on a short-term observational follow-up study of children using microscopy, RDTs and molecular detection of parasites.

\section{MATERIALS AND METHODS}

\section{Study area, participants and sampling}

The SIMI (Schistosomiasis in Mothers and Infants) community-based longitudinal study was conducted in six villages on the shores of Lake Albert and Lake Victoria in Uganda, commencing in May 2009 (Betson et al. 2010; Stothard et al. 2011, 2013). A total of 1856 mothers and children under 6 years were recruited at baseline and followed-up at 3, 6, 12 and 18 months (Lake Victoria only) later. During the SIMI study, malaria diagnosis was carried out using a combination of Paracheck-Pf ${ }^{\circledR}$ RDTs (Orchid Biomedical Systems, Goa, India) or First Response RD'Ts (HRP-2 based; Premier Medical Corporation, NJ, USA), OptiMAL RDTs (Diamed GmBH, Switzerland) and microscopy on Giemsa-stained blood films as described (Sousa-Figueiredo et al. 2010), as well as real-time PCR (see below). Prevalence levels of malaria infection in all mothers and children recruited to the SIMI study are summarized in Table 1 with stratification by lake and survey timepoint.

Bukoba village, Mayuge District, showed the highest prevalence of falciparum and non-falciparum malaria in young children (see Table 2) and so was chosen as the site for the AL follow-up study, which was conducted in November and December 2010 (Betson et al. 2010; Stothard et al. 2011). A group of children from Bukoba village $(N=163)$ within the SIMI cohort $(N=188)$ were recruited to the study on the basis of a positive First Response RDT result and microscopy-confirmed malaria. Children were subsequently followed up 7 and 17 days after day 0 (day of initiation of treatment). Due to financial and logistical constraints, only individuals who were RDT-positive on day 17 (see below), who had been given oral quinine sulphate as an alternative exit treatment, were followed up on day 24. A blood smear archive was made on days 0,7 and 17 , and confirmatory microscopy was carried out 2 or 3 days after each sample was taken (Sousa-Figueiredo et al. 2010). Blood spots were collected onto Whatman ${ }^{\circledR}$ 3MM filter paper at all timepoints for molecular analyses (see below). In addition, haemoglobin ( $\mathrm{Hb}$ ) levels were recorded for each child using a HemoCue spectrometer (HemoCue AB, Angelholm, Sweden) on days 0,7 and 17 . 
Table 1. Prevalence of malaria at different survey time points in mothers and children participating in the SIMI study at Lake Albert and Lake Victoria

\begin{tabular}{|c|c|c|c|c|c|c|c|}
\hline \multirow[b]{2}{*}{ Lake } & \multirow[b]{2}{*}{ Survey } & \multicolumn{2}{|l|}{ Mothers } & \multicolumn{2}{|l|}{ Children } & \multicolumn{2}{|l|}{ Both } \\
\hline & & Slide \% $(95 \%$ CI $)[n / N]$ & RDT \% (95\% CI) $[n / N]$ & Slide $\%(95 \%$ CI $)[n / N]$ & RDT \% (95\% CI) $[n / N]$ & Slide $\%(95 \% \mathrm{CI})[n / N]$ & RDT \% (95\% CI) $[n / N]$ \\
\hline \multirow[t]{3}{*}{ Albert } & Baseline & $22 \cdot 0(17 \cdot 6-26 \cdot 8)[72 / 328]$ & $17 \cdot 6(13 \cdot 5-22 \cdot 2)[56 / 319]$ & $60 \cdot 5(56 \cdot 4-64 \cdot 6)[339 / 560]$ & $64 \cdot 7(60 \cdot 6-68 \cdot 7)[356 / 550]$ & $46 \cdot 3(43 \cdot 0-49 \cdot 6)[411 / 888]$ & $47 \cdot 4(44 \cdot 0-50 \cdot 8)[412 / 869]$ \\
\hline & 6 months & $24 \cdot 5(19 \cdot 2-30 \cdot 4)[60 / 245]$ & $24 \cdot 3(19 \cdot 0-30 \cdot 2)[59 / 243]$ & $75 \cdot 2(70 \cdot 8-79 \cdot 3)[310 / 412]$ & $76 \cdot 0(71 \cdot 6-80 \cdot 1)[314 / 413]$ & $56 \cdot 3(52 \cdot 4-60 \cdot 1)[370 / 657]$ & $56 \cdot 9(53 \cdot 0-60 \cdot 7)[373 / 656]$ \\
\hline & 12 months & $17 \cdot 7(13 \cdot 0-23 \cdot 3)[40 / 226]$ & $14 \cdot 0(9 \cdot 9-19 \cdot 0)[34 / 243]$ & $66 \cdot 0(60 \cdot 9-70 \cdot 9)[241 / 365]$ & $68 \cdot 0(63 \cdot 2-72 \cdot 5)[274 / 403]$ & $47 \cdot 5(43 \cdot 5-51 \cdot 7)[281 / 591]$ & $47 \cdot 7(43 \cdot 8-51 \cdot 6)[308 / 646]$ \\
\hline \multirow{4}{*}{ Victoria } & Baseline & $26 \cdot 5(21 \cdot 8-31 \cdot 7)[87 / 328]$ & $26 \cdot 7(22 \cdot 0-31 \cdot 8)[88 / 330]$ & $82 \cdot 7(79 \cdot 5-85 \cdot 5)[520 / 629]$ & $86 \cdot 5(83 \cdot 6-89 \cdot 1)[551 / 637]$ & $63 \cdot 4(60 \cdot 3-66 \cdot 5)[607 / 957]$ & $66 \cdot 1(63 \cdot 0-69 \cdot 1)[639 / 967]$ \\
\hline & 6 months & $23 \cdot 7(18 \cdot 4-29 \cdot 5)[57 / 241]$ & $24 \cdot 9(19 \cdot 6-30 \cdot 9)[60 / 241]$ & $72 \cdot 4(68 \cdot 2-76 \cdot 4)[352 / 486]$ & $72 \cdot 2(68 \cdot 0-76 \cdot 2)[351 / 486]$ & $56 \cdot 3(52 \cdot 6-59 \cdot 9)[409 / 727]$ & $56 \cdot 5(52 \cdot 8-60 \cdot 2)[411 / 727]$ \\
\hline & 12 months & $30.9(24 \cdot 9-37 \cdot 5)[68 / 220]$ & $28 \cdot 9(23 \cdot 1-35 \cdot 3)[65 / 225]$ & $70 \cdot 2(65 \cdot 4-74 \cdot 7)[278 / 396]$ & $82 \cdot 7(78 \cdot 8-86 \cdot 2)[359 / 434]$ & $56 \cdot 2(52 \cdot 1-60 \cdot 1)[346 / 616]$ & $64 \cdot 3(60 \cdot 5-68 \cdot 0)[424 / 659]$ \\
\hline & 18 months & $29 \cdot 8(23 \cdot 7-36 \cdot 5)[62 / 208]$ & $35 \cdot 5(29 \cdot 1-86 \cdot 2)[77 / 217]$ & $82 \cdot 6(78 \cdot 6-86 \cdot 2)[338 / 409]$ & $88 \cdot 9(85 \cdot 5-91 \cdot 7)[384 / 432]$ & $64 \cdot 8(60 \cdot 9-68 \cdot 6)[400 / 617]$ & $71 \cdot 0(67 \cdot 4-74 \cdot 5)[461 / 649]$ \\
\hline
\end{tabular}

Table 2. Prevalence of different malaria species in mothers and children at baseline

\begin{tabular}{|c|c|c|c|c|c|c|c|c|c|}
\hline \multirow[b]{2}{*}{ Lake } & \multirow[b]{2}{*}{ Village } & \multicolumn{4}{|c|}{ Mothers } & \multicolumn{4}{|c|}{ Children } \\
\hline & & $N$ & $\begin{array}{l}\text { P. falciparum \% } \\
(95 \% \text { CI })\end{array}$ & $\begin{array}{l}\text { P. malariae } \% \\
(95 \% \mathrm{CI})\end{array}$ & $\begin{array}{l}\text { P. ovale spp. \% } \\
(95 \% \text { CI })\end{array}$ & $N$ & $\begin{array}{l}\text { P. falciparum \% } \\
(95 \% \text { CI })\end{array}$ & $\begin{array}{l}\text { P. malariae } \% \\
(95 \% \mathrm{CI})\end{array}$ & $\begin{array}{l}\text { P. ovale spp. \% } \\
(95 \% \text { CI })\end{array}$ \\
\hline \multirow{3}{*}{ Albert } & Bugoigo & 130 & $41 \cdot 5(33 \cdot 40-50 \cdot 5)$ & $1 \cdot 5(0 \cdot 2-5 \cdot 4)$ & $0(0-2 \cdot 8)$ & 216 & $65 \cdot 7(59 \cdot 0-72 \cdot 0)$ & $1 \cdot 4(0 \cdot 3-4 \cdot 0)$ & $1 \cdot 4(0 \cdot 3-4 \cdot 0)$ \\
\hline & Walukuba & 120 & $26 \cdot 1^{\mathrm{a}}(18 \cdot 4-34 \cdot 9)$ & $1 \cdot 7(0 \cdot 2-5 \cdot 9)$ & $0(0-3 \cdot 0)$ & 194 & $61 \cdot 7^{\mathrm{b}}(54 \cdot 4-68 \cdot 5)$ & $5 \cdot 2(2 \cdot 5-9 \cdot 3)$ & $0 \cdot 5(0 \cdot 01-2 \cdot 8)$ \\
\hline & Piida & 82 & $36 \cdot 6(26 \cdot 2-48 \cdot 0)$ & $0(0-4 \cdot 4)$ & $0(0-4 \cdot 4)$ & 161 & $67 \cdot 7(59 \cdot 9-74 \cdot 8)$ & $6 \cdot 2(3 \cdot 2-10 \cdot 6)$ & $0(0-4 \cdot 4)$ \\
\hline \multirow[t]{3}{*}{ Victoria } & Bugoto & 134 & $42 \cdot 5(34 \cdot 0-51 \cdot 4)$ & $1 \cdot 5(0 \cdot 2-5 \cdot 3)$ & $0(0-2 \cdot 7)$ & 258 & $79 \cdot 51(74 \cdot 0-84 \cdot 2)$ & $8 \cdot 9(5 \cdot 7-13 \cdot 1)$ & $1 \cdot 6(0 \cdot 4-3 \cdot 9)$ \\
\hline & Bukoba & 126 & $47 \cdot 6(38 \cdot 7-56 \cdot 7)$ & $2 \cdot 4(0 \cdot 5-6 \cdot 8)$ & $0 \cdot 8(0 \cdot 02-4 \cdot 3)$ & 248 & $87 \cdot 5(82 \cdot 7-91 \cdot 3)$ & $14 \cdot 5(10 \cdot 4-19 \cdot 5)$ & $8 \cdot 5(5 \cdot 3-12 \cdot 7)$ \\
\hline & Lwanika & 70 & $24 \cdot 2(14 \cdot 8-36 \cdot 0)$ & $0(0-5 \cdot 1)$ & $0(0-5 \cdot 1)$ & 133 & $79 \cdot 7(71 \cdot 9-86 \cdot 2)$ & $3 \cdot 8(1 \cdot 2-8 \cdot 6)$ & $3 \cdot 8(1 \cdot 2-8 \cdot 6)$ \\
\hline
\end{tabular}

${ }^{\mathrm{a}} N=119$.

b $N=193$. 


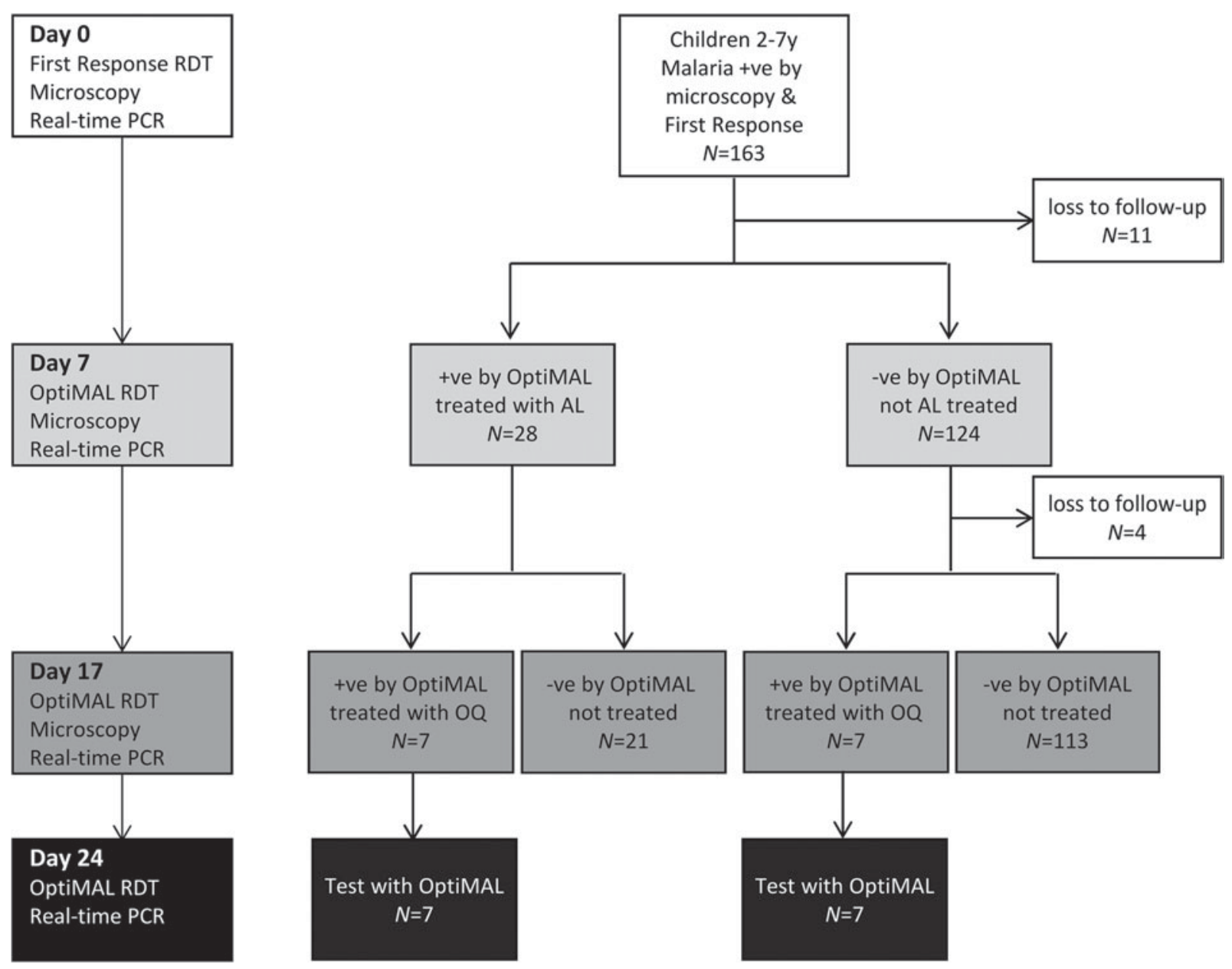

Fig. 1. Schematic representation of the study protocol, showing tests employed at each time point, numbers of participants and treatment protocol. On days 7 and 17, treatment decisions were based on the results of OptiMAL tests $(\mathrm{LDH})$ to allow rapid treatment in the field.

\section{Treatment}

To allow rapid treatment in this village setting, treatment decisions were based on the results of RDTs (Fig. 1). At baseline the HRP2-based First Response Test was used, which demonstrates very high sensitivity in detection of $P$. falciparum infections (WHO, 2008). On Days 7 and 17, treatment decisions were based on the results of the OptiMAL RDT (Diamed GmBH, Switzerland), an LDHbased test, because the LDH antigen clears much more rapidly from the blood after treatment than HRP2, with average clearance times ranging from $3 \cdot 7$ to 7 days for LDH and 20 to 28 days for HRP2 (Aydin-Schmidt et al. 2013; Nyunt et al. 2013). On day 0 all participants were treated with AL $(20 \mathrm{mg}$ artemether $120 \mathrm{mg}$ lumefantrine; LONART, Bliss Gvs Pharma Ltd., India) (WHO, 2010a). Two tablets of LONART were tested for quality and shown to contain exactly the expected amount of artemether and lumefantrine (H. Kaur, personal communication). A nurse administered the first AL dose, which was accompanied by fatty food, a mandazi (local doughnut). Subsequent AL doses were administered at home by the child's mother following the nurse's instructions. Children who were OptiMAL-positive on day 7 were treated a second time with AL. On day 17, OptiMAL-positive children were treated with oral quinine sulphate, the second-line antimalarial drug in Uganda (WHO, 2010a). At baseline children were tested for Schistosomiasis mansoni and soil-transmitted helminth infections by microscopic detection of eggs in stool as described (Katz et al. 1972; Betson et al. 2010). On day 0 all children were treated with praziquantel $\left(40 \mathrm{mg} \mathrm{kg}^{-1}\right)$ and albendazole $(400 \mathrm{mg})$ according to WHO guidelines (WHO, 2006).

\section{Molecular analysis}

To bolster microscopy findings and to detect nonfalciparum infections, genomic DNA was extracted from dried blood spots using the chelex method (Dlamini et al. 2010) and real-time PCR diagnosis of Plasmodium infections was performed as described (Shokoples et al. 2009). A Ct value of 40 was used as a cut-off to differentiate between positives and negatives for each malaria species. To distinguish between recrudescent and new falciparum infections, 


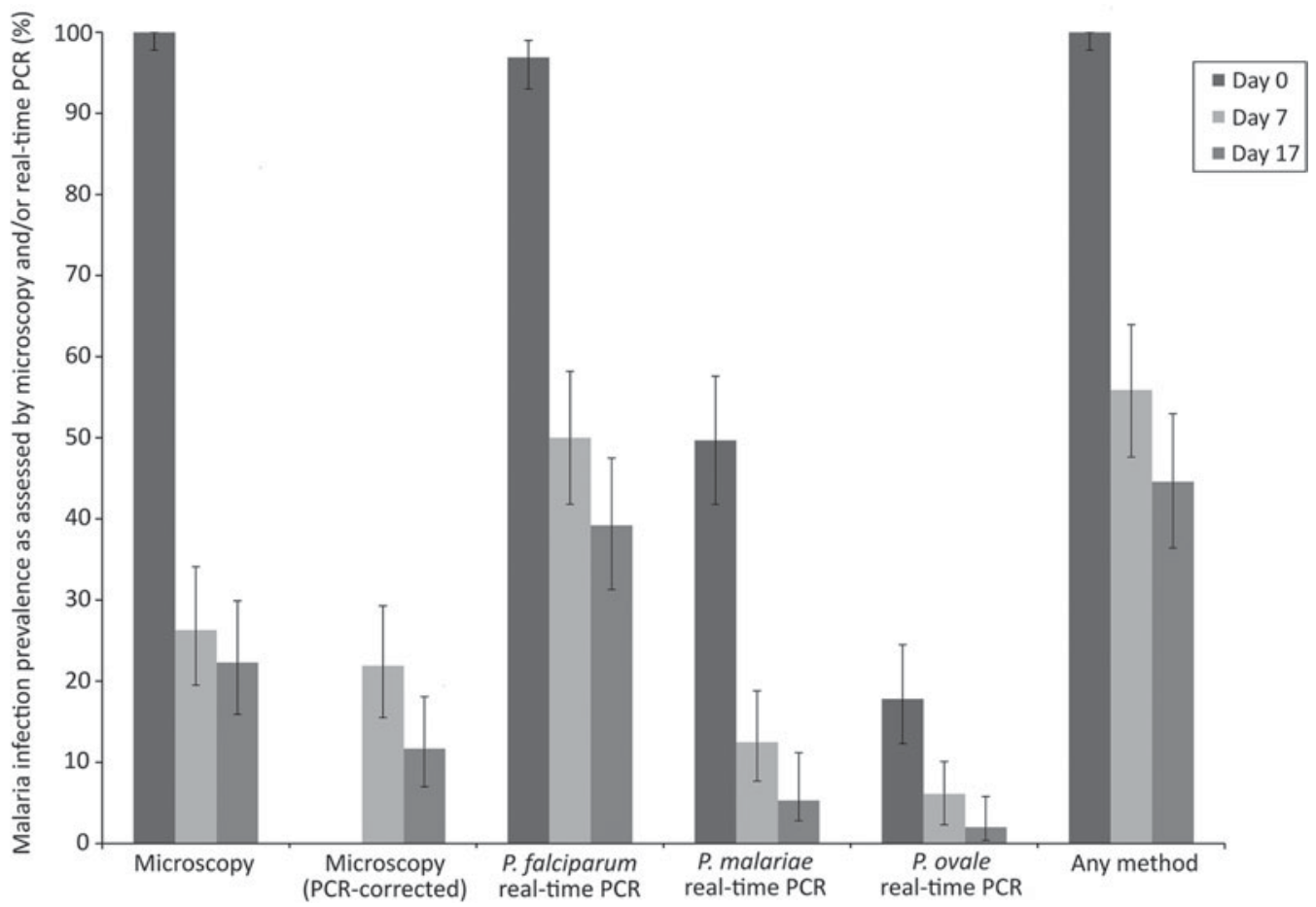

Fig. 2. Malaria infection prevalence on days 0,7 and 17 as assessed by microscopy, real-time PCR or either method. Error bars represent $95 \%$ confidence intervals.

genotyping of merozoite surface proteins ( $m s p 1$ and $m s p 2$ ) and glutamate-rich protein (glurp) was carried out according to published methods (Felger and Snounou, 2008). All PCR products were subject to polyacrylamide gel electrophoresis $(10 \%)$ and fragment sizing was carried out using a GelDoc system and Image Lab gel analysis software (Biorad, Hercules, CA, USA). Infections were classified as either recrudescent or new infections on the basis of fragment sizes (WHO, 2007).

\section{Mapping of households}

To build a comprehensive picture of spatial epidemiology of infections in the community, GPS coordinates of the households in the SIMI cohort have been collected (Stothard et al. 2011). The households of children in this study and their infection status by microscopy on days 7 and 17 were annotated using ArcView 9.3 (ESRI, CA, USA) GIS (Fig. 4). To determine whether there was any clustering of malaria infections on day 7 or day 17 , the data were analysed using a Bernoulli model in SatScan v9.2.

\section{Statistical analysis}

Epidemiological data were analysed using Stata v9.2 (StatCorp, TX, USA) and R v2.10.1 (The R Foundation for Statistical Computing, Vienna, Austria). Anaemia was categorized based on haemoglobin levels as follows: mild $10-11 \mathrm{~g} \mathrm{dL}^{-1}$, moderate $7-10 \mathrm{~g} \mathrm{dL}^{-1}$ and severe $<7 \mathrm{~g} \mathrm{dL}^{-1}$ (WHO, 2001).

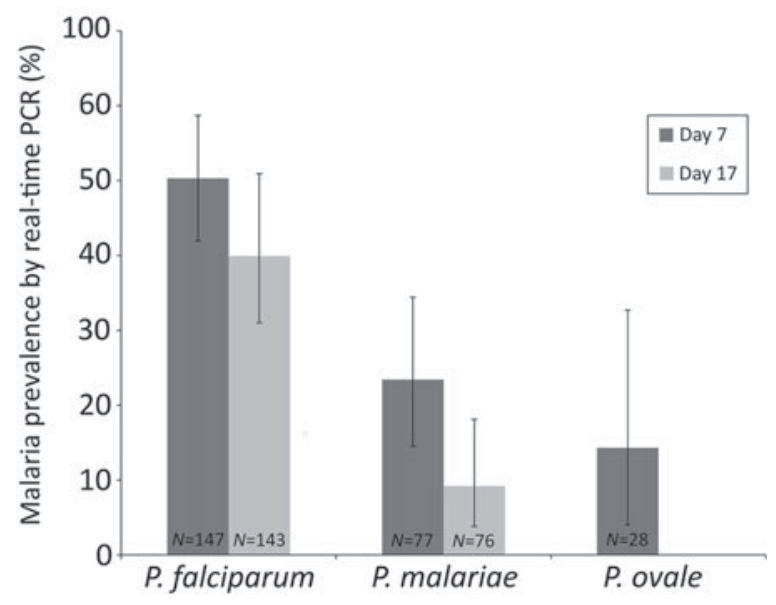

Fig. 3. Percentage of the children positive for each malaria species at baseline (as assessed by real-time PCR) who were also positive on days 7 and 17. Error bars represent $95 \%$ confidence intervals. $N=$ number of children in the denominator.

To determine how the different malaria species responded to $\mathrm{AL}$ treatment, the percentage of children infected with each species on days 7 and 17 (as assessed by real-time PCR) was calculated using the number of children infected with that species at baseline as the denominator (Fig. 3).

\section{Ethical approval}

Ethical approval was provided by The London School of Hygiene and Tropical Medicine and the Ugandan National Council of Science and 


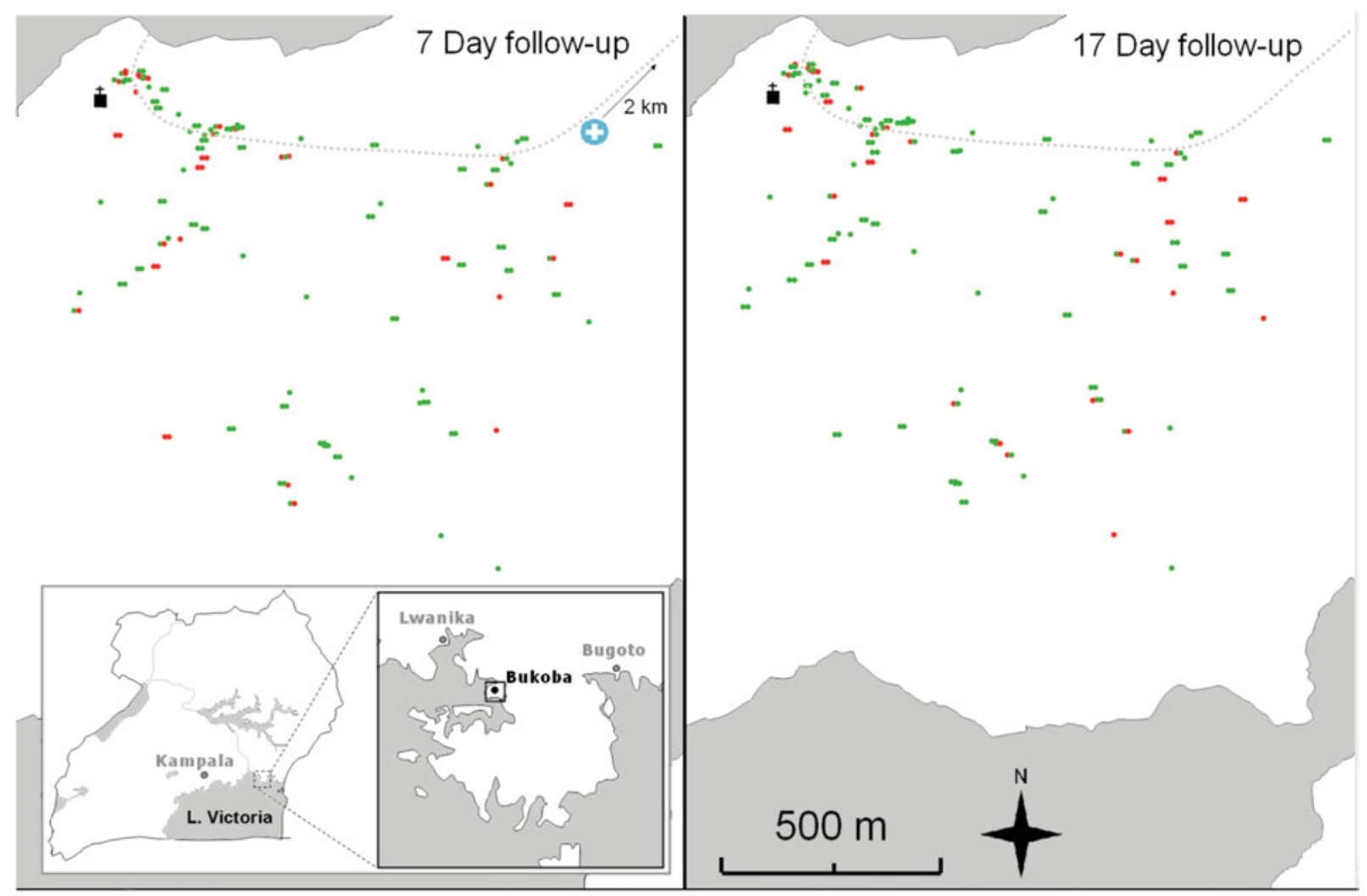

Fig. 4. From left to right: map of positive (red) and negative (green) children according to microscopy at day 7; map of positive (red) and negative (green) children according to microscopy at day 17 .

Table 3. Characteristics of AL follow-up study participants $(N=163)$ and health indicators

\begin{tabular}{lc}
\hline \hline Characteristic & Value \\
\hline Age mean (range) & \\
$\quad$ Years & $4(2-7)$ \\
Gender n (\%) & \\
$\quad$ Female & $79(48 \cdot 5)$ \\
Clinical n (\%) & \\
Axillary temperature $>37 \cdot 5{ }^{\circ} \mathrm{C}$ & $14(8 \cdot 7)$ \\
Haemoglobin $<10 \mathrm{~g} \mathrm{dL} \mathrm{L}^{-1}$ & $47(28 \cdot 8)$ \\
Hepatomegaly $^{\mathrm{a}}$ & $25(15 \cdot 5)^{\mathrm{b}}$ \\
Splenomegaly $^{\mathrm{a}}$ & $68(42 \cdot 5)^{\mathrm{c}}$ \\
S. mansoni infection $^{\mathrm{d}}$ & $3(1 \cdot 9)^{\mathrm{e}}$ \\
Hookworm infection $^{\mathrm{d}}$ & $14(9 \cdot 0)^{\mathrm{e}}$ \\
\hline
\end{tabular}

a As recorded by physical palpation according to clinical guidelines.

${ }^{\mathrm{b}} N=160$.

c $N=161$.

d Egg patent upon faecal examination.

e $N=155$.

Technology. Informed consent was given by mothers on behalf of their children and documented in writing or by thumbprint (in cases of illiteracy).

\section{RESULTS}

Table 3 details the characteristics of the AL followup study participants. The children ranged in age from $2-7$ years and $48 \cdot 5 \%$ were female. Only $8 \cdot 7 \%$ of children had low-grade fever at baseline but $28 \cdot 8 \%$ had moderate or severe anaemia. Although the prevalence of $S$. mansoni infection was very low, $9 \cdot 0 \%$ of children had egg-patent hookworm infections.

Malaria infection status at different time points is summarized in Table 4 and Fig. 2. On day 0, all 163 children were positive by microscopy with a geometric mean parasitaemia of $1640 \cdot 4$ parasites $\mu \mathrm{L}^{-1}$ blood. On day 7, 40 children $(26 \cdot 3 \%)$ remained malaria positive by microscopy and on day 17,33 children $(21 \cdot 3 \%)$ had microscopically detectable malaria infections. After genotyping using $m s p 1$, msp 2 and glurp loci, 33 out of 40 and 17 out of 33 children were shown to have recrudescent P. falciparum infections on days 7 and 17, respectively. By real-time PCR $96.9 \%$ of children were positive for $P$. falciparum on day 0 and multi-species Plasmodium infections were common, with $41 \cdot 1 \%$ positive for $P$. falciparum $/ P$. malariae, $9 \cdot 2 \%$ positive for $P$. falciparum $/ P$. ovale $\mathrm{spp}$. and $8.0 \%$ for all three species (Table 4; Fig. 2). Although there was a reduction in anaemia prevalence and severity over the course of the study, 22 children were anaemic on day 17 (Table 4).

Table 5 summarizes malaria infection in relation to number of antimalarial treatments. Eleven of the 28 children who had received two consecutive treatments with AL (on days 0 and 7) were positive by 
Table 4. Parasitaemia and prevalence of malaria infection and anaemia at days 0,7 and 17

\begin{tabular}{|c|c|c|c|c|}
\hline & & Day $0 N=163(95 \% \mathrm{CI})^{\mathrm{a}}[n]$ & Day $7 N=152(95 \% \mathrm{CI})[n]$ & Day $17 N=148(95 \% \mathrm{CI})[n]$ \\
\hline Parasitaemia (parasites $\mu \mathrm{L}^{-1}$ ) & $\begin{array}{l}\text { Geometric mean } \\
\text { Range }\end{array}$ & $\begin{array}{l}1640 \cdot 4(1298 \cdot 1-2073 \cdot 0) \\
20-90640\end{array}$ & $\begin{array}{l}578 \cdot 7(351 \cdot 0-954 \cdot 2) \\
31 \cdot 4-10360\end{array}$ & $\begin{array}{l}457 \cdot 7(185 \cdot 2-1131 \cdot 1) \\
5 \cdot 4-101080\end{array}$ \\
\hline Prevalence by microscopy (\%) & $\begin{array}{l}\text { Any parasitaemia } \\
1-500\left(\text { parasites } \mu \mathrm{L}^{-1}\right) \\
500-2000\left(\text { parasites } \mu \mathrm{L}^{-1}\right) \\
2000-10000\left(\text { parasites } \mu \mathrm{L}^{-1}\right) \\
>10000\left(\text { parasites } \mu \mathrm{L}^{-1}\right) \\
\text { PCR-corrected }(P . \text { falciparum only) }\end{array}$ & $\begin{array}{l}100(97 \cdot 8-100)[163] \\
18 \cdot 4(12 \cdot 8-25 \cdot 2)[30] \\
37 \cdot 4(30 \cdot 0-45 \cdot 3)[61] \\
33 \cdot 1(26 \cdot 0-40 \cdot 9)[54] \\
11 \cdot 1(6 \cdot 7-16 \cdot 9)[18] \\
-\end{array}$ & $\begin{array}{l}26 \cdot 3(19 \cdot 5-34 \cdot 1)[40] \\
9 \cdot 9(5 \cdot 6-15 \cdot 8)[15] \\
9 \cdot 9(5 \cdot 6-15 \cdot 8)[15] \\
5 \cdot 9(2 \cdot 7-10 \cdot 9)[9] \\
0 \cdot 7(0 \cdot 02-3 \cdot 6)[1] \\
21 \cdot 9(15 \cdot 5-29 \cdot 3)^{\mathrm{b}}[33]\end{array}$ & $\begin{array}{l}22 \cdot 3(15 \cdot 9-29 \cdot 9)[33] \\
10 \cdot 1(5 \cdot 8-16 \cdot 2)[15] \\
8 \cdot 1(4 \cdot 3-13 \cdot 7)[12] \\
0 \cdot 7(0 \cdot 01-3 \cdot 7)[1] \\
3 \cdot 4(1 \cdot 1-7 \cdot 7)[5] \\
11 \cdot 7(7 \cdot 0-18 \cdot 1)^{\mathrm{c}}[17]\end{array}$ \\
\hline Prevalence by real-time PCR (\%) & $\begin{array}{l}\text { P. falciparum } \\
\text { P. malariae } \\
\text { P. ovale spp. }\end{array}$ & $\begin{array}{l}96 \cdot 9(93 \cdot 0-99 \cdot 0)[158] \\
49 \cdot 7(41 \cdot 8-57 \cdot 6)[81] \\
17 \cdot 8(12 \cdot 3-24 \cdot 5)[29]\end{array}$ & $\begin{array}{l}50 \cdot 0(41 \cdot 8-58 \cdot 2)[76] \\
12 \cdot 5(7 \cdot 7-18 \cdot 8)[19] \\
5 \cdot 3(2 \cdot 3-10 \cdot 1)[8]\end{array}$ & $\begin{array}{l}39 \cdot 2(31 \cdot 3-47 \cdot 5)[58] \\
6 \cdot 1(2 \cdot 8-11 \cdot 2)[9] \\
2 \cdot 0(0 \cdot 4-5 \cdot 8)[3]\end{array}$ \\
\hline $\begin{array}{l}\text { Prevalence of mixed infections } \\
\text { by real-time PCR }(\%)\end{array}$ & $\begin{array}{l}P . \text { falciparum } / P . \text { malariae } \\
P . \text { falciparum } / P \text {. ovale } \mathrm{spp} \text {. } \\
P . \text { falciparum } / P \text {. malariae } / P \text {. ovale spp. }\end{array}$ & $\begin{array}{l}41 \cdot 1(33 \cdot 5-49 \cdot 1)[67] \\
9 \cdot 2(5 \cdot 2-14 \cdot 7)[15] \\
8 \cdot 0(4 \cdot 3-13 \cdot 3)[13]\end{array}$ & $\begin{array}{l}10 \cdot 5(6 \cdot 1-16 \cdot 5)[16] \\
3 \cdot 3(1 \cdot 1-7 \cdot 5)[5] \\
1 \cdot 3(0 \cdot 2-4 \cdot 7)[2]\end{array}$ & $\begin{array}{l}5 \cdot 4(2 \cdot 4-10 \cdot 4)[8] \\
1 \cdot 4(0 \cdot 2-4 \cdot 8)[2] \\
0 \cdot 7(0 \cdot 01-3 \cdot 7)[1]\end{array}$ \\
\hline Prevalence of anaemia (\%) & $\begin{array}{l}\text { Any anaemia } \\
\text { Mild } \\
\text { Moderate } \\
\text { Severe }\end{array}$ & $\begin{array}{l}56 \cdot 4(48 \cdot 5-64 \cdot 2)[92] \\
27 \cdot 6(20 \cdot 1-35 \cdot 1)[45] \\
27 \cdot 6(20 \cdot 1-35 \cdot 1)[45] \\
1 \cdot 2(0 \cdot 1-4 \cdot 4)[2]\end{array}$ & $\begin{array}{l}45 \cdot 4(37 \cdot 3-53 \cdot 7)[69] \\
27 \cdot 6(20 \cdot 1-35 \cdot 5)[42] \\
17 \cdot 8(12 \cdot 0-24 \cdot 8)[27] \\
0\end{array}$ & $\begin{array}{l}14 \cdot 9(9 \cdot 6-21 \cdot 6)[22] \\
10 \cdot 8(6 \cdot 3-17 \cdot 0)[16] \\
4 \cdot 1(1 \cdot 5-8 \cdot 6)[6] \\
0\end{array}$ \\
\hline
\end{tabular}

a $95 \% \mathrm{CI}=95 \%$ confidence interval.

b $N=151$.

c $N=145$. 
Table 5. Summary of percentages of children who were malaria positive by PCR on days 17 and 24 after one or two antimalarial treatments

\begin{tabular}{|c|c|c|c|c|c|c|}
\hline & & \multirow[b]{2}{*}{ Treatment(s) } & \multicolumn{2}{|c|}{ Day 17} & \multicolumn{2}{|c|}{ Day $24^{\mathrm{a}}$} \\
\hline & & & $N$ & $\%$ & $N$ & $\%$ \\
\hline \multirow{2}{*}{\multicolumn{2}{|c|}{ Microscopy }} & $1 \mathrm{AL}$ & 120 & $18 \cdot 3$ & NS & $\mathrm{NS}$ \\
\hline & & $2 \mathrm{AL}$ & 28 & $39 \cdot 3$ & NS & $\mathrm{NS}$ \\
\hline \multirow[t]{6}{*}{ Real-time PCR } & P. falciparum & $1 \mathrm{AL}$ & 120 & $35 \cdot 0$ & 7 & $57 \cdot 1$ \\
\hline & & $2 \mathrm{AL}$ & 28 & $57 \cdot 1$ & 7 & $85 \cdot 7$ \\
\hline & P. malariae & $1 \mathrm{AL}$ & 120 & $2 \cdot 5$ & 7 & 0 \\
\hline & & $2 \mathrm{AL}$ & 28 & $21 \cdot 4$ & 7 & $28 \cdot 6$ \\
\hline & P. ovale spp. & $1 \mathrm{AL}$ & 120 & $0 \cdot 8$ & 7 & 0 \\
\hline & & $2 \mathrm{AL}$ & 28 & $7 \cdot 1$ & 7 & 0 \\
\hline
\end{tabular}

a All children who were followed up on day 24 had been treated with oral quinine on day 17.

$1 \mathrm{AL}=$ one $\mathrm{AL}$ treatment, $2 \mathrm{AL}=$ two AL treatments; $N=$ total number of individuals; $\mathrm{NS}=$ no slides.

microscopy on Day 17. At this timepoint, 16 children were $P$. falciparum positive by real-time PCR, six children were infected with $P$. malariae and two with $P$. ovale spp. On day 24 , after two or three consecutive antimalarial treatments, 10 children were infected with $P$. falciparum and two were also infected with P. malariae (Table 5). When the performance of AL on different Plasmodium species was investigated, $39.9 \%$ of the children infected with falciparum malaria at baseline were still $P$. falciparum positive on Day 17, whereas $9 \cdot 2 \%$ of those who were $P$. malariae positive at baseline showed $P$. malariae infection on Day 17 (Fig. 3).

To determine whether there were differing risks of infection after treatment for children living in different parts of the village, their households and infection status on days 7 and 17 were mapped (Fig. 4). Spatial analysis using SatScan suggested six possible clusters of positive children on both day 7 and day 17. However, the statistical support for each cluster was low with $P$ values greater than $0 \cdot 1$ in each case (data not shown). Thus strong evidence for clustering of malaria infections after AL treatment was not found, although this may reflect a lack of power due to the small numbers of infected individuals on days 7 and 17 .

\section{DISCUSSION}

In light of the challenges in diagnosis of falciparum and non-falciparum malaria and the chronically high prevalence of infections in Bukoba village, Uganda, we document the short-term effect of AL treatment on multiple malaria species in a cohort of young children living in this area. The study was designed to gain insights into treatment responses when $\mathrm{AL}$ was distributed to parasitaemic children in a communitybased setting (unsupervised treatment), rather than as a carefully controlled standard efficacy trial. It is outside the remit of this paper to explore how well the results of standard efficacy trials predict the effectiveness of home-based management strategies in the same population. However, we found by microscopy that $26 \cdot 3 \%$ of treated children $(21.9 \%$ recrudescent by PCR genotyping) showed $P$. falciparum parasitaemia 7 days after treatment and that $22.3 \%$ (11.7\% recrudescent) had parasites in their blood after 17 days, despite the fact that $33 \%$ of these positive children had already been retreated with AL at day 7. A substantial number of additional recurrent infections were identified by real-time PCR, including P. malariae and P. ovale spp. infections. Although none of these infections could be considered 'complicated' clinical malaria, their significance needs to be better quantified.

Our results are surprising given that clinical trials of AL in Uganda using microscopic diagnosis found that parasite clearance was rapid (very few detectable infections by day 3), there was negligible risk of parasitaemia before day 21 and that risks of treatment failure by day 28 ranged from 1-9\% (Bukirwa et al. 2006; Dorsey et al. 2007; Kamya et al. 2007; Yeka et al. 2008; Achan et al. 2009; Arinaitwe et al. 2009; The Four Artemisinin-Based Combinations (4ABC) Study Group, 2011). In contrast, a trial in Ghana found day 28 failure rates of 14\% (Owusu-Agyei et al . 2008) and a longitudinal community-based study in Papua New Guinea found a PCR-corrected parasitological treatment failure rate of $19 \cdot 8 \%$ for $\mathrm{AL}$ (Schoepflin et al. 2011). Although artemisinintolerant falciparum has been reported in East Asia (Noedl et al. 2008; Dondorp et al. 2009), there has been little evidence to date of reduced efficacy of AL in Africa in standard clinical trials. Borrmann et al. reported a small decline in parasitological response rates to ACTs (including $\mathrm{AL}$ ) in coastal Kenya (Borrmann et al. 2011). However, it is unclear whether this change reflected increased tolerance of the parasite to ACTs or reductions in clinical immunity due to decreased malaria transmission. In a number of African countries there appears to be selection for $86 \mathrm{~N}, 184 \mathrm{~F}$ and $1246 \mathrm{D}$ alleles in the 
product of the $P$. falciparum multidrug-resistant 1 gene $(p f m d r 1)$ in recurrent infections soon after AL treatment (Humphreys et al. 2007; Baliraine and Rosenthal, 2011; Gadalla et al. 2011). These polymorphisms as well as pfmdr1 amplification have been associated with decreased sensitivity of P. falciparum in vitro to AL (Price et al. 2006). Thus, there is potential for tolerance to $\mathrm{AL}$ to develop in Africa.

This study was based on assessment of parasitaemia rather than clinical illness and most children had asymptomatic infections on day 0 . The 21-day efficacy of the ACT dihydroartemisinin piperiquine (DP) for treatment of $P$. falciparum in parasitaemic but asymptomatic Ghanaian schoolchildren was $91 \%$ and it was suggested that chronic asymptomatic infections may not respond as well to antimalarial treatment as symptomatic infections because the parasites do not stimulate immune responses which can assist in parasite clearance (Dinko et al. 2013). In our study the performance was much lower, but there was no significant difference in the treatment responses of children with higher parasitaemia ( $>2000$ parasites $\mu \mathrm{L}^{-1}$ ) and those with lower parasitaemia (data not shown). Similar responses to AL were also observed when children with fever or moderate/severe anaemia on day 0 were compared with those with no fever or anaemia. However, the number of symptomatic individuals in our study may be too small to detect subtle differences in responses to AL treatment between symptomatic and asymptomatic individuals.

There has been little work assessing the dynamics of parasite clearance after AL treatment using PCR, although a median clearance time of 2 days has been reported (Aydin-Schmidt et al. 2013). However, additional submicroscopic infections have been detected in children during post-treatment followup using PCR (Gadalla et al. 2011; Aydin-Schmidt et al. 2013; Beshir et al. 2013; Dinko et al. 2013), as we report here. The importance of such sub-patent malaria infections was recently demonstrated by Beshir et al. in Kenya, who showed that residual sub-microscopic parasitaemia on day 3 after commencement of AL or DP treatment was associated with longer gametocyte carriage, increased transmission to mosquitoes and recurrence of microscopically detectable malaria infections on day 24 or day 48 (Beshir et al. 2013). The incorporation of PCR-based malaria diagnosis into the standard protocols of ACT efficacy studies will be important to determine the extent of submicroscopic carriage of malaria parasites after treatment.

The vast majority of $P$. malariae and $P$. ovale infections detected by real-time PCR at baseline were mixed infections with $P$. falciparum, which were difficult to detect on thick films despite crosschecking. Plasmodium malariae was not fully sensitive to AL in this study as around 9\% of infected individuals were still positive on day 17 , and two children were $P$. malariae positive at day 24 after three antimalarial treatments. The fact that $50 \%$ of study participants were infected with $P$. malariae and $18 \%$ with $P$. ovale indicates that the number of mixed infections receiving ACTs is substantially larger than previously thought. Mombo-Ngoma et al. reported, in 38 Gabonese patients, a 28-day cure rate by microscopy of $100 \%$ for AL in treatment of $P$. malariae, $P$. ovale and mixed infections in Gabon, although post hoc PCR revealed that only 19 of the patients in the study had been correctly diagnosed with non-falciparum malaria (MomboNgoma et al. 2012). In contrast, Dinko et al. detected persistent $P$. malariae and $P$. ovale spp. infections in Ghanaian schoolchildren 21 days after ACT treatment using qPCR as the endpoint measure (Dinko et al. 2013). Therefore we strongly advocate that further studies are needed to understand the response of non-falciparum malaria to ACT treatment, and these should deploy molecular parasite detection as the primary endpoint. The development of specific molecular diagnostic tests for field-based detection of $P$. malariae and $P$. ovale spp. would be of great assistance in these endeavours.

It must be borne in mind that our study did not formally determine how well the participants complied with the approved antimalarial treatment regime, i.e. two doses a day for 3 days after consumption of fatty food (WHO, 2010a). Measurement of day 7 lumefantrine levels in our participants would have provided a means to verify adequate dosing. Thus, poor compliance may at least partially explain why some of the children remained parasitaemic after two or three doses of antimalarial medication. It must also be noted that de-worming drugs, praziquantel and albendazole, were coadministered with AL. There is a paucity of information on the putative interactions of anthelmintics with antimalarial drugs, and more research on this topic is warranted, especially given the changing landscape of mass drug administration in sub-Saharan Africa (WHO, 2010b). There are additional limitations to the analysis presented here. First, due to logistical constraints, study participants were only followed up for 17 or 24 days. It would have been preferable to extend this period to 28 or 42 days after treatment to allow a more direct comparison with published efficacy studies. Second, the real-time PCR analysis did not distinguish between asexual parasites and gametocytes. Although no gametocytes were observed by microscopy after AL treatment (data not shown), it is possible that sub-microscopic gametocytes were present. Third, it is possible that the proportion of new infections on day 7 and day 17 as determined by PCR genotyping is overestimated. Alleles can remain undetected using the recommended genotyping procedure particularly if they represent low abundance clones, leading to 
misclassification of recrudescences as new infections (Juliano et al. 2010). However, there is also the possibility of misclassifying new infections as recrudescences in areas of intense transmission, as children can be re-infected with parasites of the same genotype as the original infection. Thus care should be exercised when interpreting PCR 'corrected' results.

\section{CONCLUSION}

The burden of malaria remains high in Uganda. Whilst the Ugandan malaria policy promotes AL as the first-line antimalarial treatment and is doubtless saving many lives, other challenges in its implementation remain. Our results suggest that even though ACTs remain highly efficacious in treatment of clinical disease in sub-Saharan Africa, asymptomatic and submicroscopic falciparum and non-falciparum infections often persist after treatment. These infections may be significant in terms of later recurrence of clinical disease and parasite transmission. Improved diagnostics are needed for field-based detection of non-falciparum malaria infections, gametocytes and drug-resistance markers. Increased communitybased surveillance using a range of diagnostic tests is required to provide further insights into the extent of persistent parasitaemia after ACT treatment and for early detection of ACT-tolerant parasites in subSaharan Africa. Finally, new in vivo study protocols, with sensitive molecular endpoints, must now be developed that are specifically designed to measure the efficacy of antimalarial regimens against asymptomatic and sub-patent Plasmodium spp. infections.

\section{ACKNOWLEDGEMENTS}

We are extremely grateful to the participating children and their guardians. We also gratefully acknowledge the field assistance of technicians of the Vector Control Division and local community mobilizers. We thank Dr Harparkash Kaur for verifying the composition of our study medicines. MB would like to thank the BSP for support to attend the BSP Symposium on 'Advances in diagnostics for infectious diseases' at Ness Gardens in September 2013.

\section{FINANCIAL SUPPORT}

This work was supported by the Wellcome Trust (grant number WT085440MA). CJS is supported by Public Health England.

\section{REFERENCES}

Achan, J., Tibenderana, J. K., Kyabayinze, D., Wabwire Mangen, F., Kamya, M. R., Dorsey, G., D'Alessandro, U., Rosenthal, P. J. and Talisuna, A. O. (2009). Effectiveness of quinine versus artemetherlumefantrine for treating uncomplicated falciparum malaria in Ugandan children: randomised trial. British Medical Fournal 339, b2763.

Arinaitwe, E., Sandison, T. G., Wanzira, H., Kakuru, A., Homsy, J., Kalamya, J., Kamya, M. R., Vora, N., Greenhouse, B., Rosenthal, P. J., Tappero, J. and Dorsey, G. (2009). Artemetherlumefantrine versus dihydroartemisinin-piperaquine for falciparum malaria: a longitudinal, randomized trial in young Ugandan children. Clinical Infectious Diseases 49, 1629-1637.

Aydin-Schmidt, B., Mubi, M., Morris, U., Petzold, M., Ngasala, B. E. Premji, Z., Bjorkman, A. and Martensson, A. (2013). Usefulness of Plasmodium falciparum-specific rapid diagnostic tests for assessment of parasite clearance and detection of recurrent infections after artemisininbased combination therapy. Malaria fournal 12, 349.

Baliraine, F. N. and Rosenthal, P. J. (2011). Prolonged selection of $p f m d r 1$ polymorphisms after treatment of falciparum malaria with artemetherlumefantrine in Uganda. Fournal of Infectious Diseases 204, 1120-1124.

Bassat, Q., Mulenga, M., Tinto, H., Piola, P., Borrmann, S., Menendez, C., Nambozi, M., Valea, I., Nabasumba, C., Sasi, P., Bacchieri, A., Corsi, M., Ubben, D., Talisuna, A. and D'Alessandro, U. (2009). Dihydroartemisinin-piperaquine and artemether-lumefantrine for treating uncomplicated malaria in African children: a randomised, non-inferiority trial. PLoS One 4, e7871.

Batwala, V., Magnussen, P. and Nuwaha, F. (2010). Challenges to implementation of artemisinin combination therapy policy in Uganda. International Health 2, 262-268.

Beshir, K. B., Sutherland, C. J., Sawa, P., Drakeley, C. J., Okell, L., Mweresa, C. K., Omar, S. A., Shekalaghe, S. A., Kaur, H., Ndaro, A., Chilongola, J., Schallig, H. D., Sauerwein, R. W., Hallett, R. L. and Bousema, T. (2013). Residual Plasmodium falciparum parasitemia in Kenyan children after artemisinin-combination therapy is associated with increased transmission to mosquitoes and parasite recurrence. Fournal of Infectious Diseases 208, 2017-2024.

Betson, M., Sousa-Figueiredo, J. C., Rowell, C., Kabatereine, N. B. and Stothard, J. R. (2010). Intestinal schistosomiasis in mothers and young children in Uganda: investigation of field-applicable markers of bowel morbidity. American Fournal of Tropical Medicine and Hygiene 83, 1048-1055.

Borrmann, S., Sasi, P., Mwai, L., Bashraheil, M., Abdallah, A., Muriithi, S., Fruhauf, H., Schaub, B., Pfeil, J., Peshu, J., Hanpithakpong, W., Rippert, A., Juma, E., Tsofa, B., Mosobo, M., Lowe, B., Osier, F., Fegan, G., Lindegardh, N., Nzila, A., Peshu, N., Mackinnon, M. and Marsh, K. (2011). Declining responsiveness of Plasmodium falciparum infections to artemisinin-based combination treatments on the Kenyan coast. PLoS One 6, e26005.

Bruce, M. C., Macheso, A., Kelly-Hope, L. A., Nkhoma, S., McConnachie, A. and Molyneux, M. E. (2008). Effect of transmission setting and mixed species infections on clinical measures of malaria in Malawi. PLoS One 3, e2775.

Bukirwa, H., Yeka, A., Kamya, M. R., Talisuna, A., Banek, K., Bakyaita, N., Rwakimari, J.B., Rosenthal, P. J., WabwireMangen, F., Dorsey, G. and Staedke, S. G. (2006). Artemisinin combination therapies for treatment of uncomplicated malaria in Uganda. PLoS Clinical Trials 1, e7.

Collins, W. E. and Jeffery, G. M. (2005). Plasmodium ovale: parasite and disease. Clinical Microbiology Reviews 18, 570-581.

Collins, W. E. and Jeffery, G. M. (2007). Plasmodium malariae: parasite and disease. Clinical Microbiology Reviews 20, 579-592.

Dinko, B., Oguike, M. C., Larbi, J.A., Bousema, T. and Sutherland, C. J. (2013). Persistent detection of Plasmodium falciparum, $P$. malariae, $P$. ovale curtisi and $P$. ovale wallikeri after ACT treatment of asymptomatic Ghanaian school-children. International fournal for Parasitology: Drugs and Drug Resistance 3, 45-50.

Dlamini, S. V., Beshir, K. and Sutherland, C. J. (2010). Markers of antimalarial drug resistance in Plasmodium falciparum isolates from Swaziland: identification of pfmdr1-86F in natural parasite isolates. Malaria Fournal 9, 68 .

Dondorp, A. M., Nosten, F., Yi, P., Das, D., Phyo, A. P., Tarning, J., Lwin, K. M., Ariey, F., Hanpithakpong, W., Lee, S. J., Ringwald, P., Silamut, K., Imwong, M., Chotivanich, K., Lim, P., Herdman, T., An, S. S., Yeung, S., Singhasivanon, P., Day, N. P., Lindegardh, N., Socheat, D. and White, N. J. (2009). Artemisinin resistance in Plasmodium falciparum malaria. New England Fournal of Medicine 361, 455-467. Dorsey, G., Staedke, S., Clark, T. D., Njama-Meya, D., Nzarubara, B., Maiteki-Sebuguzi, C., Dokomajilar, C., Kamya, M. R. and Rosenthal, P. J. (2007). Combination therapy for uncomplicated falciparum malaria in Ugandan children: a randomized trial. Fournal of the American Medical Association 297, 2210-2219.

Drakeley, C. and Reyburn, H. (2009). Out with the old, in with the new: the utility of rapid diagnostic tests for malaria diagnosis in Africa. Transactions of the Royal Society of Tropical Medicine and Hygiene 103, 333-337.

Felger, I. and Snounou, G. (2008). Recommended Genotyping Procedures (RGPs) to Identify Parasite Populations. Medicine for Malaria Venture and World Health Organization, Geneva, Switzerland. 
Fogg, C., Bajunirwe, F., Piola, P., Biraro, S., Checchi, F., Kiguli, J., Namiiro, P., Musabe, J., Kyomugisha, A. and Guthmann, J. P. (2004) Adherence to a six-dose regimen of artemether-lumefantrine for treatment of uncomplicated Plasmodium falciparum malaria in Uganda. American Fournal of Tropical Medicine and Hygiene 71, 525-530.

Gadalla, N. B., Adam, I., Elzaki, S. E., Bashir, S., Mukhtar, I., Oguike, M., Gadalla, A., Mansour, F., Warhurst, D., El-Sayed, B. B. and Sutherland, C. J. (2011). Increased $p f m d r 1$ copy Number and sequence polymorphisms in Plasmodium falciparum isolates from Sudanese malaria patients treated with artemether-lumefantrine. Antimicrobial Agents and Chemotherapy 55, 5408-5411.

Houzé, S., Hubert, V., Cohen, D. P., Rivetz, B. and Le Bras, J. (2011). Evaluation of the Clearview $(\mathrm{R})$ malaria $\mathrm{pLDH}$ malaria rapid diagnostic test in a non-endemic setting. Malaria fournal 10, 284

Humphreys, G.S., Merinopoulos, I., Ahmed, J., Whitty, C. J., Mutabingwa, T. K., Sutherland, C. J. and Hallett, R. L. (2007). Amodiaquine and artemether-lumefantrine select distinct alleles of the Plasmodium falciparum $m d r 1$ gene in Tanzanian children treated for uncomplicated malaria. Antimicrobial Agents and Chemotherapy 51, 991-997.

Juliano, J. J., Gadalla, N., Sutherland, C. J. and Meshnick, S. R. (2010) The perils of PCR: can we accurately 'correct' antimalarial trials? Trends in Parasitology 26, 119-124.

Kamya, M. R., Yeka, A., Bukirwa, H., Lugemwa, M., Rwakimari, J. B., Staedke, S. G., Talisuna, A. O., Greenhouse, B., Nosten, F., Rosenthal, P. J., Wabwire-Mangen, F. and Dorsey, G. (2007). Artemether-lumefantrine versus dihydroartemisinin-piperaquine for treatment of malaria: a randomized trial. PLoS Clinical Trials 2, e20. Katz, N., Chaves, A. and Pellegrino, J. (1972). A simple device for quantitative stool thick-smear technique in Schistosomiasis mansoni. Revista do Instituto de Medicina Tropical de Sao Paulo 14, 397-400.

Maltha, J., Gillet, P. and Jacobs, J. (2013a). Malaria rapid diagnostic tests in endemic settings. Clinical Microbiology and Infection 19, 399-407. Maltha, J., Gillet, P. and Jacobs, J. (2013b). Malaria rapid diagnostic tests in travel medicine. Clinical Microbiology and Infection 19, 408-415.

Mombo-Ngoma, G., Kleine, C., Basra, A., Wurbel, H., Diop, D. A., Capan, M., Adegnika, A. A., Kurth, F., Mordmuller, B., Joanny, F., Kremsner, P. G., Ramharter, M. and Belard, S. (2012). Prospective evaluation of artemether-lumefantrine for the treatment of non-falciparum and mixed-species malaria in Gabon. Malaria fournal 11, 120.

Mueller, I., Zimmerman, P. A. and Reeder, J. C. (2007). Plasmodium malariae and Plasmodium ovale - the "bashful" malaria parasites. Trends in Parasitology 23, 278-283.

Mueller, I., Galinski, M. R., Baird, J. K., Carlton, J. M., Kochar, D. K., Alonso, P. L. and del Portillo, H. A. (2009). Key gaps in the knowledge of Plasmodium vivax, a neglected human malaria parasite. Lancet Infectious Diseases 9, 555-566.

Noedl, H., Se, Y., Schaecher, K., Smith, B. L., Socheat, D. and Fukuda, M. M. (2008). Evidence of artemisinin-resistant malaria in western Cambodia. New England Journal of Medicine 359, 2619-2620.

Nyunt, M. H., Kyaw, M. P., Win, K. K., Myint, K. M. and Nyunt, K. M. (2013). Field evaluation of HRP2 and pan pLDH-based immunochromatographic assay in therapeutic monitoring of uncomplicated falciparum malaria in Myanmar. Malaria fournal 12, 123

Oguike, M. C., Betson, M., Burke, M., Nolder, D., Stothard, J. R., Kleinschmidt, I., Proietti, C., Bousema, T., Ndounga, M., Tanabe, K. Ntege, E., Culleton, R. and Sutherland, C. J. (2011). Plasmodium ovale curtisi and Plasmodium ovale wallikeri circulate simultaneously in African communities. International fournal for Parasitology 41, 677-683.

Owusu-Agyei, S., Asante, K.P., Owusu, R., Adjuik, M., AmengaEtego, S., Dosoo, D. K., Gyapong, J., Greenwood, B. and Chandramohan, D. (2008). An open label, randomised trial of artesunate + amodiaquine, artesunate + chlorproguanil-dapsone and artemether-lumefantrine for the treatment of uncomplicated malaria. PLOS ONE 3, e2530. Piola, P., Fogg, C., Bajunirwe, F., Biraro, S., Grandesso, F., Ruzagira, E., Babigumira, J., Kigozi, I., Kiguli, J., Kyomuhendo, J.,
Ferradini, L., Taylor, W., Checchi, F. and Guthmann, J. P. (2005). Supervised versus unsupervised intake of six-dose artemether-lumefantrine for treatment of acute, uncomplicated Plasmodium falciparum malaria in Mbarara, Uganda: a randomised trial. Lancet 365, 1467-1473

Price, R. N., Uhlemann, A.C., van Vugt, M., Brockman, A., Hutagalung, R., Nair, S., Nash, D., Singhasivanon, P., Anderson, T. J., Krishna, S., White, N. J. and Nosten, F. (2006) Molecular and pharmacological determinants of the therapeutic response to artemether-lumefantrine in multidrug-resistant Plasmodium falciparum malaria. Clinical Infectious Diseases 42, 1570-1577.

Proietti, C., Pettinato, D. D., Kanoi, B. N., Ntege, E., Crisanti, A., Riley, E. M., Egwang, T. G., Drakeley, C. and Bousema, T. (2011). Continuing intense malaria transmission in northern Uganda. American Fournal of Tropical Medicine and Hygiene 84, 830-837.

Schoepflin, S., Lin, E., Kiniboro, B., DaRe, J.T., Mehlotra, R. K., Zimmerman, P. A., Mueller, I. and Felger, I. (2011). Treatment with coartem (artemether-lumefantrine) in Papua New Guinea. American Fournal of Tropical Medicine and Hygiene 82, 529-534.

Shokoples, S. E., Ndao, M., Kowalewska-Grochowska, K. and Yanow, S. K. (2009). Multiplexed real-time PCR assay for discrimination of Plasmodium species with improved sensitivity for mixed infections. Fournal of Clinical Microbiology 47, 975-980.

Sousa-Figueiredo, J.C., Oguttu, D., Adriko, M., Besigye, F., Nankasi, A., Arinaitwe, M., Namukuta, A., Betson, M., Kabatereine, N. B. and Stothard, J. R. (2010). Investigating portable fluorescent microscopy (CyScope) as an alternative rapid diagnostic test for malaria in children and women of child-bearing age. Malaria fournal $\mathbf{9}, 245$ Stothard, J. R., Sousa-Figueiredo, J. C., Betson, M., Seto, E. Y. and Kabatereine, N. B. (2011). Investigating the spatial micro-epidemiology of diseases within a point-prevalence sample: a field applicable method for rapid mapping of households using low-cost GPS-dataloggers. Transactions of the Royal Society of Tropical Medicine Hygiene 105, 500-506.

Stothard, J. R., Sousa-Figueiredo, J.C., Betson, M., Bustinduy, A. and Reinhard-Rupp, J. (2013). Schistosomiasis in African infants and preschool children: let them now be treated! Trends in Parasitology 29, 197-205.

The Four Artemisinin-Based Combinations (4ABC) Study Group (2011). A head-to-head comparison of four artemisinin-based combinations for treating uncomplicated malaria in African children: a randomized trial. PLoS Medicine 8, e1001119.

WHO (2001). Iron Deficiency Anaemia: Assessment, Prevention and Control. World Health Organization, Geneva, Switzerland.

WHO (2006). Preventive Chemotherapy in Human Helminthiasis. World Health Organization, Geneva, Switzerland.

WHO (2007). Methods and Techniques for Clinical Trials on Antimalarial Drug Efficacy: Genotyping to Identify Parasite Populations. Medicines for Malaria Venture and World Health Organization, Geneva, Switzerland. WHO (2008). Malaria Rapid Diagnostic Test Performance. World Health Organization, Geneva, Switzerland.

WHO (2010a). Guidelines for the Treatment of Malaria. World Health Organization, Geneva, Switzerland.

WHO (2010b). Working to Overcome the Global Impact of Neglected Tropical Diseases. First WHO Report on Neglected Tropical Diseases. World Health Organization, Geneva, Switzerland

WHO (2012). Malaria Rapid Diagnostic Test Performance. Results of WHO Product Testing of Malaria RDTs: Round 4 (2012). World Health Organization, Geneva, Switzerland.

Yeka, A., Dorsey, G., Kamya, M. R., Talisuna, A., Lugemwa, M., Rwakimari, J. B., Staedke, S. G., Rosenthal, P. J., WabwireMangen, F. and Bukirwa, H. (2008). Artemether-lumefantrine versus dihydroartemisinin-piperaquine for treating uncomplicated malaria: a randomized trial to guide policy in Uganda. PLoS One 3, e2390.

Yeka, A., Gasasira, A., Mpimbaza, A., Achan, J., Nankabirwa, J., Nsobya, S., Staedke, S. G., Donnelly, M. J., Wabwire-Mangen, F., Talisuna, A., Dorsey, G., Kamya, M. R. and Rosenthal, P. J. (2012). Malaria in Uganda: challenges to control on the long road to elimination I. Epidemiology and current control efforts. Acta Tropica 121, 184-195. 